\title{
miscellany
}

\section{Lancet Paper of the Year Award}

WHITTINGTON, C. J., KENDALL,T., FONAGY, P., COTTRELL, D., COTGROVE, A. \& BODDINGTON, E. (2004) Selective serotonin reuptake inhibitors in childhood depression: systematic review of published versus unpublished data. Lancet, $\mathbf{3 6 3}$, 1341-1345.

College members (Craig Whittington, Tim Kendall, Peter Fonagy, David Cottrell, Andy Cotgrove and Ellen Boddington) were authors of the Lancet Paper of the Year, awarded in December 2004 and referred to by the Editor as 'one of the most stunning and influential systematic reviews in recent years'.

The paper was selected by the Lancet's International Advisory Board and Editors from among any paper worldwide published in a scientific or medical journal between October 2003 and October 2004.

The paper compared the results of two meta-analyses: one using only published randomised controlled trials; the second combining the published and unpublished trials, all obtained by the Medicines and Healthcare Products Regulatory Agency (MHRA) from drug companies. The published trials suggested that for the four selective serotonin reuptake inhibitors (SSRIs) examined (fluoxetine, sertraline, paroxetine and venlafaxine) there was a weak but positive riskbenefit ratio. When these data were combined with the unpublished data the risk-benefit ratios were reversed for all except fluoxetine. This supported the decision of the MHRA to contraindicate the use of SSRIs (except fluoxetine) for children and adolescents with depression.

The importance of the paper lies in the fact that it presented concrete metaanalytical evidence of the potentially dangerous effects of publication bias and/or the failure to publish negative results by drug companies (selective publishing).

\section{forthcoming events}

The Mental Health Nurses Association (MHNA) would like to announce their 2005 annual conference, Travelling Together - Developing The Skills For Inclusive Mental Healthcare, which is taking place on 10-12 November 2005 at the Bournemouth International Centre. The conference will be of benefit to all with an interest in mental health, including mental health nurses, psychologists and psychiatrists. The theme of inclusion runs throughout the conference programme, with keynote speakers, concurrent sessions and skills-based workshops concentrating on the development of policy and practice of working inclusively. For further information please contact the conference organisers: Profile Productions Ltd, Northumberland House,
11 The Pavement, Popes Lane, London W5 4NG (tel: 0208832 7311, fax: 0208832 7301,e-mail: info@profileproductions. co.uk, website: http://www.profile productions.co.uk)

Patient Safety 2006 will take place on 1-2 February 2006 at the International Convention Centre in Birmingham. Building on the huge success of Patient Safety 2004, this innovative event will explore the issues surrounding the creation of safer healthcare. Participants will be able to tailor-make their own event using 'tracks' - a series of themes incorporating workshops and presentations. There will be presentations by internationally acclaimed speakers and interactive sessions. To register and receive further information please visit the following website: http://www. patientsafety 2006.nhs.uk. Alternatively, please send an e-mail to enquiries@patient safety2006.nhs.uk or telephone +44020 82332827

The International Early Psychosis Association (IEPA) conference Beyond the Crossroads will take place on 3-6 October 2006 at the International Convention Centre in Birmingham. For further information please contact the event organisers, Happenings Australia (tel: +61 39866 6288, fax +6139866 6313, e-mail: event@happenings.com.au, website: http://www.happenings. com.au). 